\title{
A Importância da Propaganda Médica para o sucesso da Indústria Farmacêutica e a Diferença que o Propagandista faz para a Classe Médica e seus Pacientes
}

\author{
Bruno Lima e Santos ${ }^{1}$; Thais Angela Rodrigues dos Santos $^{2}$; Hesler Piedade Caffé Filho ${ }^{3}$
}

\begin{abstract}
Resumo: O referido estudo tem por objetivo, destacar a importância da propaganda médica para o sucesso da indústria farmacêutica, e a diferença que o propagandista faz para a classe médica e seus pacientes. Por ser uma das indústrias mais rentáveis e lucrativas do mundo contemporâneo, as companhias farmacêuticas também sofrem com a alta competitividade, o que leva a busca incessante de profissionais cada vez mais qualificados e assertivos na busca de resultados em curto prazo. A temática justifica-se em razão da importância estratégica dos propagandistas de medicamentos para a indústria farmacêutica, sendo uma das indústrias que mais investem em pesquisa na atualidade, e contribuem para promoção da saúde e qualidade de vida da população. A pesquisa caracteriza-se como qualitativa com delineamento descritivo-exploratório, cujo embasamento se dá através de pesquisa bibliográfica. Utilizou-se a metodologia de análise de conteúdo através dos artigos pesquisados. Os resultados demonstram que a Indústria Farmacêutica utiliza-se do propagandista médico como principal ferramenta de propaganda e estratégia de vendas, assim este profissional necessita de capacitação contínua e deve estar pronto para aceitar e superar os desafios impostos pela concorrência no segmento farmacêutico. Através da visitação a classe médica e farmácias, o propagandista consegue construir uma ponte entre a Indústria Farmacêutica e o paciente, promovendo saúde e bem-estar. Dessa forma, pode-se notar o importante papel desempenhado pelo propagandista e a relevância que este profissional tem para a indústria farmacêutica, para a classe médica e para a população em geral.
\end{abstract}

Palavras-chave: Propaganda Médica, Propagandista, Indústria Farmacêutica, Visitação Médica, Segmento Farmacêutico.

\section{The Importance of Medical Advertising for the Success of the Pharmaceutical Industry and the Difference that the Advertising Agent makes for the Medical Class and its Patients}

\begin{abstract}
This study aims to highlight the importance of medical advertising for the success of the pharmaceutical industry, and the difference that the propagandist makes for the medical profession and its patients. As one of the most profitable and profitable industries in the contemporary world, pharmaceutical companies also suffer from high competitiveness, which leads to the incessant search for increasingly qualified and assertive professionals in the search for results in the short term. The theme is justified due to the strategic importance of drug propagandists for the pharmaceutical industry, being one of the industries that invest the most in research today, and contribute

\footnotetext{
${ }^{1}$ Graduado em Processos Gerenciais pela Universidade Norte do Paraná - UNOPAR, Pós-Graduando em Gestão Comercial e Marketing pela Faculdade São Francisco de Juazeiro - FASJ, atualmente Propagandista Médico na Hypera Farma. limaebruno@uol.com.br

${ }^{2}$ Graduada em Fisioterapia pela Universidade Estadual de Ciências da Saúde de Alagoas - UNCISAL, Pós-Graduanda em Gestão Comercial e Marketing pela Faculdade São Francisco de Juazeiro - FASJ, atualmente Propagandista Médico na Eurofarma. thais.angela1985@gmail.com

${ }^{3}$ Graduado em Administração pela Estácio de Sá, Pós-Graduado em Gestão Estratégica de Negócios pela Esc. Eng. Eletromecânica da Bahia - EMBA, Pós-Graduado em Marketing Institucional pela Faculdade São Francisco de Juazeiro FASJ, Mestrando em Gestão de Políticas Públicas pela Universidade Federal do Recôncavo da Bahia - UFRB. Atualmente, Administrador e Docente da Pós-Graduação em Gestão Pública da Universidade Federal do Vale do São Francisco - UNIVASF e Docente Carreira Superior da FASJ - Faculdade São Francisco de Juazeiro. hesler.caffe@ univasf.edu.br
} 
to the promotion of health and quality of life of the population. The research is characterized as qualitative with a descriptive-exploratory design, which is based on bibliographic research. The content analysis methodology was used through the researched articles. The results demonstrate that the Pharmaceutical Industry uses the medical propagandist as the main advertising tool and sales strategy, so this professional needs continuous training and must be ready to accept and overcome the challenges imposed by competition in the pharmaceutical segment. Through visits to the medical profession and pharmacies, the propagandist manages to build a bridge between the Pharmaceutical Industry and the patient, promoting health and well-being. Thus, one can note the important role played by the propagandist and the relevance that this professional has for the pharmaceutical industry, for the medical profession and for the population in general.

Keywords: Medical Advertising, Propagandist, Pharmaceutical Industry, Medical Visitation, Pharmaceutical Segment.

\section{Introdução}

A Indústria Farmacêutica é um dos segmentos de maior relevância no cenário mundial, tanto pela promoção à saúde da população, quanto pelo valor faturado. Apesar de ser um segmento diferenciado, a indústria farmacêutica precisa inovar sempre pois estamos tratando de um mercado cada vez mais competitivo, levando seus profissionais do marketing a encontrar meios que maximizem seus resultados.

Neste cenário a visita médica é sua grande arma usada pelo marketing, haja visto, ser o local onde tal profissional e a companhia podem se consagrar, pois o cliente médico, se torna aliado, tanto para o paciente, quanto para quem conseguir trazer-lhe produtos com segurança e qualidade (KOTLER; SIMON, 2004).

As indústrias farmacêuticas, através de ações pontuais de marketing, têm como objetivo, informar aos parceiros da área de saúde a respeito das novidades e seus respectivos benefícios para a população, e para isso, necessitam de qualidade, além de um aporte financeiro, transformado em tecnologias e pesquisas, para assim, melhorar a eficácia de seus produtos. É comum e necessária a troca de informações entre os partícipes deste conjunto, empresas e clientes, para que assim, o todo saia com melhores resultados (MUSSOLINI, 2010).

É fato, que a visita médica deve ser muito mais que informações sobre segurança, qualidade e preço para os clientes finais. É determinante um excelente conhecimento técnico na hora do fechamento do negócio, além de uma estrutura impecável, oferecida pela companhia, para que consiga, através de dados, muitas vezes científicos, e boa empatia, convencer os clientes médicos e consumidores finais, acerca dos diferenciais em relação à concorrência, bem como a tão esperada melhoria da saúde geral dos pacientes.

Através de informações verídicas, o médico indica determinados produsots, de empresas éticas, produtos que detenham uma qualidade e ação comprovada e inquestionável. Com base 
nessas informações, estas empresas visam levar saúde à população, não apenas o lucro (MUSSOLINI, 2010).

A indústria farmacêutica precisa estar em constante evolução para sobreviver num meio corporativo tão competitivo. O mundo dos negócios necessita de adaptação e resultados em curto prazo, e em razão desta mudança contínua, o desempenho, as competências e habilidades do capital humano tornam-se fundamentais, fazendo do propagandista de medicamentos uma ferramenta imprescindível neste cenário seletivo.

Neste sentido o propagandista de medicamentos com sua metodologia de análise, enfoque, desenvolvimento pessoal e profissional e aprimoramento de suas competências tende a ampliar seu desempenho e elevar os resultados vislumbrados num curto espaço de tempo.

Com a proposta de gerar uma intersecção entre a Indústria Farmacêutica, Propaganda Médica, Médico e Paciente, esta pesquisa visa responder ao seguinte questionamento: "qual a importância da Propaganda Médica para o sucesso da Indústria Farmacêutica?"

Nesta perspectiva tem-se como objetivo geral pesquisar em literaturas específicas no que consiste o papel do Propagandista Médico e sua potencialidade como ferramenta estratégica no sucesso da obtenção de resultados da profissão.

A pesquisa tem como objetivos específicos:

- Descrever o papel do Propagandista de Medicamentos;

- Verificar a diferença que o Propagandista faz para a Classe Médica;

- Analisar a importância da Visita Médica para os pacientes.

Como justificativa do tema, os autores da pesquisa salientam a total relação entre a atividade que atuam profissionalmente como Propagandistas de medicamentos na área de vendas com o interesse despertado pelo MBA de Gestão Comercial e Marketing, dessa forma almeja-se com a resposta do problema da pesquisa, auxiliar no crescimento e desenvolvimento de suas carreiras profissionais.

O desenvolvimento da pesquisa se dará em seis capítulos, sendo que no segundo capítulo será descrito a relevância da Indústria Farmacêutica no cenário nacional, visto que sua importância refere-se tanto ao volume de investimentos em pesquisas para promoção da saúde como sua alta lucratividade no mercado global.

Já no terceiro capítulo a pesquisa abordará o papel do Propagandista Médico, suas habilidades e competências e sua relação direta como profissional do marketing e vendas, bem como a abordagem sugerida pelo profissional na execução do seu trabalho.

O capítulo quatro tratará da importância da Propaganda Médica para o sucesso da Indústria Farmacêutica. Faz-se notório neste capítulo a relevância dada ao desenvolvimento 
destes profissionais que estão em constante treinamento e aperfeiçoamento para levar informações precisas a fim de serem cada vez mais assertivos.

Por conseguinte, no quinto capítulo, tratar-se-á da diferença que o Propagandista faz para a Classe Médica e seus pacientes, abordando condutas necessárias para o sucesso do propagandista na visita médica.

Por fim o sexto capítulo descreverá as considerações finais extraídas da pesquisa, bem como a conclusão a que se refere o alcance dos objetivos específicos e a resposta ao problema da pesquisa.

O desafio está lançado com o objetivo de encontrar respostas que possibilitem ampliar a obtenção de resultados da profissão de Propagandista Médico em que os pesquisadores estão inseridos diretamente, através da identificação do perfil, das habilidades e competências exigidas pela profissão norteando o profissional na busca da ascensão profissional.

\section{A Indústria Farmacêutica}

Atualmente, a Indústria Farmacêutica é uma das principais atividades que movimentam o mercado, devido a sua importância para as pessoas, o mundo e a ciência, visto que ela desenvolve pesquisas para lançar novos produtos com a finalidade de promover saúde a população como um todo. Desta forma, assim como as outras indústrias, espera-se obter vantagens e lucro sobre os investimentos em pesquisa e desenvolvimento no menor espaço de tempo possível.

Neste contexto, surge a figura dos propagandistas vendedores de medicamentos, que são os profissionais da Indústria Farmacêutica responsáveis por promover e comercializar os produtos aos seus clientes. São estes profissionais que geram a demanda para a indústria, através da propaganda médica.

$\mathrm{Na}$ atualidade, a Indústria Farmacêutica exerce um papel importante para a ciência, em razão dos grandes investimentos realizados em pesquisas e em desenvolvimento de medicamentos, visando solucionar problemas ligados à saúde como prevenir futuras doenças, chegando a movimentar bilhões de dólares em investimentos no desenvolvimento, pesquisa, marketing e promoção destes produtos, junto a médicos e pesquisadores, tornando-se uma das indústrias mais inventivas, inovadoras e rentáveis do globo, mesmo atuando num mercado fortemente regulamentado e de alta competitividade (ROCHA, 2002; KESIC, 2009; DAS, 2011). 
Kappe (2011) destaca que a Industria Farmacêutica é considerada como uma das mais importantes indústrias para manter a saúde e prolongar a vida, no entanto, para manter-se competitiva, precisa ser uma indústria lucrativa.

Segundo dados da ABIFARMA (2012), no mercado brasileiro atuam 369 empresas, sendo $17 \%$ delas de capital estrangeiro e $83 \%$ de capital nacional, gerando algo em torno de 50.000 empregos diretos e 250.000 indiretos. O mercado farmacêutico brasileiro representa US\$ 34 bilhões, impulsionado principalmente pelo número de vendas dos medicamentos genéricos.

Os países emergentes como o Brasil possuem um mercado atraente para a Indústria Farmacêutica, onde o mercado brasileiro já é o $8^{\circ}$ maior mercado farmacêutico do mundo. (IMS MARKET 2010-2014). Neste cenário, o crescimento do mercado brasileiro e fortalecimento da nossa economia, tem promovido maior aporte de investimentos de empresas farmacêuticas multinacionais, que concentram seus esforços na ampliação e construção de fábricas e aumento de suas unidades de negócios, especialmente a sua força de vendas.

\section{Propagandista Médico}

Em 14 de julho de 1975, a lei 6.224 regulamentou o exercício da profissão de propagandista vendedor de produtos farmacêuticos. Essa é uma função extremamente importante para os laboratórios - que dependem do bom desempenho do propagandista para a divulgação de seus medicamentos - e para os médicos, que são atualizados constantemente das novidades que surgem no mercado.

O propagandista da Indústria Farmacêutica tem a pretensão de cumprir um papel importante para o meio médico e para a sociedade atuando como "auxiliar na atualização dos médicos quanto a lançamentos de medicamentos pelo laboratórios, novos estudos e formas de tratamento de determinada doença com um produto já conhecido, mas que tenha uma nova posologia ou via de administração”. (SILVA; LOVATO JUNIOR, 2016, p.1).

As empresas do ramo farmacêutico investem constantemente em treinamentos e reciclagens dos propagandistas. Para ingressar e exercer a atividade de propagandista, os laboratórios buscam profissionais com curso superior, em alguns casos exigem pós-graduação, porém buscam profissionais que têm disposição ao estudo contínuo e que sejam pessoas que demonstrem atitudes baseadas em competências-chave.

De acordo com os dados analisados e resultados da pesquisa de Silva e Lovato Júnior (2016), o perfil do propagandista é constituído pelos dois gêneros, masculino e feminino, entre 
idade de 27 e 32 anos, nível educacional superior e domínio de ao menos uma língua estrangeira. O propagandista deve ser organizado, apto a cumprir metas e tolerar controles de suas atividades (preenchimento de relatórios, reuniões periódicas). Deve também tolerar o trabalho intenso e estressante e reagir positivamente às práticas motivacionais explícitas do segmento farmacêutico.

Segundo Fortes (2017), atualmente, no Brasil, 98\% da promoção médica é feita por meio de visitas dos propagandistas aos médicos e apenas $2 \%$ é feita por outros canais, como telemarketing, web, e-mail-s entre outros. A revista UpPharma (maio e junho de 2016) relata que "a profissão do propagandista é uma das que mais passa por transformações ao longo dos anos". [...] O propagandista farmacêutico desenvolve um trabalho complexo, exaustivo, que exige perseverança, paciência e foco na obtenção de resultados e no atingimento de metas.

Para Vieira (2011, p.18) "Uma técnica para acelerar o desenvolvimento profissional nas visitas, é não atender, mas sim entender o que os clientes necessitam, vai ser através deste que irá possibilitar atender as necessidades do médico e consequentemente ganhar seu receituário". Faz-se necessário não só conhecer as necessidades dos nossos clientes, mas encantá-los. O limiar entre o interesse de promover a venda e ser interessante diante do médico é muito tênue.

Hoje, o profissional de propaganda médico, é a alma das empresas de medicamento (NETZ, 2001). No intuito de alcançar grades resultados e ser reconhecido nesta carreira, este profissional precisa ter um perfil empreendedor, ser resiliente, ter um bom relacionamento interpessoal, e ser honesto (FASSOLD, 2002).

Fortes $(2017$, p.04) destaca que "as características necessárias para um propagandista são: conhecimento técnico, organização, agilidade, empatia, paciência, criatividade, disciplina, determinação, adaptabilidade e flexibilidade e principalmente persuasão".

Percebe-se que quanto maior o relacionamento entre propagandista e médico mais fácil se torna a prescrição dos medicamentos por meio do médico. Fortes (2017) afirma que "o trabalho constante do representante com o médico, age como uma espécie de marketing de relacionamento no qual o foco principal dessa relação é o poder de convencimento do representante perante o médico".

Segundo Vieira (2011, p.25), "se o propagandista dominar os principais benefícios do seu medicamento a ser propagado e malefícios dos medicamentos dos seus concorrentes, ele maximiza a possibilidade de ganhar receituário do médico". É preciso analisar a concorrência, verificar o produto que mais cresce e quem gera esta demanda, e criar estratégias para desenvolver um diferencial competitivo em relação aos concorrentes. Também faz parte do dia 
a dia do propagandista identificar o melhor horário e forma pessoal e intelectual que o médico prefere ser abordado.

Além disso, Vieira (2011, p.24) traz a necessidade do propagandista gerenciar seu território de atuação identificando regiões que ofereça um maior percentual de demanda e os principais médicos daquele setor; elaborando roteiros eficazes para minimizar a possibilidade de perda de tempo e diminuir custos, estreitar seu relacionamento com balconista com intuito de minimizar as eventuais trocas de receitas, verificar se o medicamento está em falta ou exposto de maneira incorreta, gerenciar o material de merchandising com seu emprego de maneira coerente nos pontos de vendas. Precisa identificar seus concorrentes (pontos fortes e fracos) para direcionar a propaganda como um plano estratégico.

Sendo o vendedor, o principal instrumento que faz a ponte entre a empresa e o comprador, e que através da venda cria-se um bom relacionamento, busca-se assim longevidade nessa troca (NASCIMENTO, 2008).

\section{A Importância da Propaganda Médica para o Sucesso da Indústria Farmacêutica}

A Indústria Farmacêutica, é uma das mais importantes fontes de pesquisa no mundo científico, pois é através dela que surgem impressionantes descobertas de moléculas que tornam a vida humana cada dia mais longeva e saudável. Diante destas descobertas e através de todos os trâmites legais que cada molécula precisa passar até poder ser liberada para a utilização em humanos, se faz necessária um amplo conhecimento sobre esta, atrelada a uma divulgação qualificada e direcionada àqueles que passarão a lançar mão, utilizando com conhecimento e segurança deste novo conceito. Assim, cria-se um importante vínculo entre a Indústria Farmacêutica, o Propagandista Médico, o Médico e por fim o Paciente.

Neste mercado atuam grandes corporações mundiais, que chegam a investir bilhões de dólares no desenvolvimento e comercialização de seus produtos (DAS, 2011). É fato, que se faz necessário que sejam criadas e colocadas em prática, estratégias que tornem tais investimentos rentáveis para estas companhias, a relocação de mais valores para que sejam pesquisadas e criadas cada vez mais produtos a serem disponibilizados a médicos e pacientes.

Kremer et al., (2008) defendem que os recursos direcionados ao marketing farmacêutico se justificam por possibilitarem aos fabricantes farmacêuticos mais inovadores, a oportunidade para recuperar seus altos investimentos com Pesquisa e Desenvolvimento (P \& D), servindo inclusive como um canal de comunicação para educar os médicos e expor aos consumidores as informações que podem melhorar os resultados de saúde, e para isso realizam ações promocionais e comerciais junto aos médicos que são os prescritores dos medicamentos e junto 
aos canais de distribuição competentes (farmácias, distribuidores) buscando alcançar os objetivos planejados. É daí, que justifica-se, através de órgãos reguladores estatais, no caso do Brasil, a ANVISA, leis que regulamentam a ação, seja de Marketing, Propaganda (Publicidade e Propaganda, além de Propaganda Médica), Merchandising e Eventos Médicos (onde se enquadram eventos de Educação Continuada Médica, Simpósios e Congressos, dentre outros). Fonte: Dos autores, baseado em (WAZANA, 2000; FUGH, 2007; PALÁCIOS, 2008; GAGNON, 2008; SANVITO, 2012).

Assim define-se o quão importante é e sempre será esta importante ferramenta utilizada pela Indústria Farmacêutica, para apoiar cada vez mais, estas Companhias, a levarem investimentos nesta cadeia inesgotável de inovação para o cotidiano de todos nós que dependemos de produtos que melhorem nosso vida como um todo.

Segundo Cesar (2005), utiliza-se o marketing de relacionamento para divulgar novos produtos com eficácia. Esta abordagem é feia pelos profissionais de propaganda médica, colocando em prática técnicas de contato e venda, alinhando as informações passadas pelas empresas e juntando a isso a entrega de materiais científicos, brindes, amostras grátis, e afins, com o objetivo de tornar os produtos propagados mais destacados que os da concorrência, levando mais benefícios para cada cliente médico. Alguns médicos levam em consideração apenas preço, enquanto que outros aliam além do preço, a qualidade de cada um.

Com o intuito de massificar a marca de cada produto/laboratório, estas companhias investem de forma pesada na qualificação do seu quadro de profissionais da propaganda médica, através de treinamentos, além de contribuir para uma educação continuada para a classe médica, por meio da participação em estudos clínicos, reunião com profissionais da área, eventos científicos, publicação de trabalhos, congressos, anúncio em revistas especializadas, amostras grátis, brindes e etc. (NETZ, 2001).

Fassold (2002) afirma que o profissional de propaganda médica é considerado pela classe médica, tanto de especialistas, quanto de Clínica Geral, como a melhor forma que eles tem, de adquirir informações precisas sobre os produtos das empresas, pois os profissionais de propaganda médica, através de sua forma empática de visita-los, são especializados em seus produtos, são confiáveis, criativos e honestos.

Os feedbacks sobre o giro dos produtos comercializados, tornam as empresas de marketing de relacionamento, importantes parceiras, pois norteiam as ações de cada companhia, através do acompanhamento de campo, traduzido pelos relatórios mensais e semestrais, aferindo assim os resultados de cada setor. (NASCIMENTO, 2008). 
O bom relacionamento é fundamental para o sucesso de suas vendas e ter habilidade em lidar com pessoas é premissa para o sucesso da profissão. "Os médicos, por conta do número grande de pacientes que precisam atender, têm pouco tempo para dar atenção aos propagandistas. Estes profissionais do marketing precisam ter a habilidade de passar a informação dos medicamentos com objetividade e clareza".

Para os medicamentos que necessitam de prescrição uma das formas mais utilizadas para a divulgação é a propaganda médica. A maioria dos laboratórios contrata profissionais, esses são chamados de representantes ou propagandistas. $\mathrm{O}$ trabalho deles é realizar visitas periódicas aos médicos apresentando os seus lançamentos ou apenas reforçando a linha já existente, distribuindo algumas amostras para os médicos iniciarem o tratamento com pacientes, eles percorrem uma média de 15 médicos por dia, gastando cerca de 5 a 10 minutos por visita para convencer o médico sobre as vantagens de seu produto. O retorno desse trabalho para a indústria farmacêutica é imenso, pois a partir do momento que o médico receita, a venda é garantida. Isso justifica o alto investimento que é feito para esse tipo de propaganda, que hoje já possui quase 30 mil profissionais.

No Brasil a propaganda de medicamentos é regulamentada pela constituição federal de 1988 e uma série de leis decretos e resoluções que estabelecem a forma rígida como deve ser feita a propaganda de medicamentos (ANVISA, 2004).

Para os medicamentos de prescrição a propaganda é restrita aos meios de comunicação destinados exclusivamente a profissionais de saúde habilitados a prescrever ou dispensar produtos, ou sejam médicos, veterinários e odontólogos. Ela deve incluir determinadas informações sobre o medicamento como posologia, indicações, contra indicações e classificação. Não é permitida a propaganda direta ao consumidor nem a comunicação direta com o proprietário da farmácia ou os balconistas.

Mussolini (2010) acredita que as companhias farmacêuticas, através de ações promocionais, têm a finalidade de informar os profissionais da saúde sobre as inovações e seus benefícios para a população, para isso precisam atingir um bom patamar qualitativo e um grande investimento tecnológico, e pesquisas a fim de melhorar a eficácia dos seus medicamentos. Assim, faz-se útil e necessário as trocas de informações entre empresas e clientes do ramo para bons negócios ou parcerias entre médicos e pacientes.

\section{A Diferença que o Propagandista faz para a Classe Médica e seus Pacientes}


Diante do crescente número de moléculas descobertas, suas utilizações, e forma como estas devem ser prescritas, de acordo com todas as pesquisas laboratoriais e clínicas, faz-se necessário, para o apoio e incentivo à inesgotável necessidade de maior conhecimento sobre o assunto, um acompanhamento por parte da Indústria Farmacêutica, e por intermédio de um Profissional treinado e apto a este contato junto à Classe Médica, para assim levar estudos e publicações científicas, além de "amostras grátis" destas medicações, para que seja feita uma observação "in loco" dos benefícios dessas novidades.

São contatos, na maioria das vezes, realizados mensalmente, porém, existem Companhias Farmacêuticas que realizam estes contatos, estrategicamente, em períodos quinzenais. Estes contatos levam a estes Profissionais, informações acerca de Publicações realizadas em grandes encontros médicos, leia-se, Simpósios, Congressos e etc., onde devido à falta de tempo e também pelo fator custo, a maioria da Classe Médica não tem como se fazerem presentes.

De acordo com esta atuação, o Propagandista da Indústria Farmacêutica, cumpre a especial função, de através de uma frequência e sequência em suas visitas a este cliente Médico, de chegar à parcela principal deste ciclo que é o Paciente.

Em muitos casos, ele o paciente, não entende a função do Propagandista frente ao Médico, se irritando com a presença destes nas Clínicas, Consultórios, Hospitais, dentre outros. Não conseguindo assim, ligar os elos que através dos Propagandistas da Indústria Farmacêutica, fazem estes mesmos pacientes chegarem de forma mais rápida e segura à saúde e cura que buscam, através das prescrições assertivas e embasadas, em muitos casos, pelas informações levadas por estes Propagandistas.

Desta forma, podemos destacar, o quão diferenciada é a atuação destes profissionais de Propaganda Médica, ao traduzirem em uma maior velocidade, a chegada de novos tratamentos, embasados por estudos científicos, na prescrição destes medicamentos, levando mais saúde a toda a população.

Na visão de Bregantin (2002), para que o propagandista desempenhe sua função de maneira eficaz, ele deve tomar ciência que ele é o profissional com maior capacidade de atualização para informar a classe médica, sobre seu produto e para isso deve seguir alguns fatores necessários para concluir sua visitação.

a) A imagem da empresa que representa: O propagandista carrega consigo a imagem da empresa. O médico pode ter uma imagem desta empresa construída pelo antigo representante ou por alguma medicação que não atendeu suas expectativas de maneira satisfatória. Caso a empresa não tenha uma boa credibilidade no mercado o propagandista sofrerá seus efeitos 
frente ao médico, que pode ter uma opinião já formada, e não interagir de maneira satisfatória com o profissional.

b) A qualidade da formação técnica: Um dos pilares do sucesso na visita médica é um profissional capacitado. É imprescindível que o propagandista médico tenha um bom conhecimento técnico para se portar frente ao médico, pois é este profissional que levará informações relevantes e convincentes para persuadí-lo. Além das empresas exigirem a graduação em nível superior, os propagandistas estão em constante treinamento, seja técnico ou comercial, sempre buscando a excelência na prestação de serviço a classe médica.

c) A qualidade do treinamento recebido: $O$ treinamento é fundamental para a formação do novo propagandista. Faz-se necessário conhecer bem os produtos antes de propagá-lo, assim como os pontes fortes e fracos do seu produto e dos concorrentes. Estes treinamentos são de suma importância para que esclareçam todas as dúvidas e incertezas da classe médica. Dessa forma, o propagandista bem preparado estará seguro frente ao médico para abordá-lo da maneira mais assertiva em busca dos seus resultados.

d) A qualidade do material promocional: Nas visitas, além do conhecimento técnico e comercial, o propagandista pode disponibilizar literaturas, fascículos, artigos científicos apresentados em Congressos, High Light, revistas, dentre outros materiais que possam agregar valor ao seu trabalho junto a classe médica, além das amostras grátis de medicamentos. Assim, com o auxílio do material promocional pode-se contribuir para a atualização contínua dos médicos, além de proporcionar melhor entendimento sobre as abordagens de tratamento apresentadas.

e) O bom senso ao perguntar: Com a experiência do campo e relacionamento com os clientes médicos, o propagandista consegue no seu dia a dia identificar qual o melhor momento e abordagem frente ao médico para conseguir a informação pertinente para o seu negócio, o que permite descobrir o porquê da prescrição de tal produto ou do seu concorrente. O propagandista além de ser bom na arte da persuasão, necessita antes de tudo ser um excelente ouvinte, pois muitas informações estão nas entrelinhas do bate-papo com o médico e a secretária.

f) O pronto atendimento às solicitações médicas: Para manter uma parceria de sucesso com a classe médica, o propagandista deve está disponível para atender as dúvidas e solicitações médicas quanto a estudos e amostras. Essa relação de confiança é construída diariamente com as visitas e relacionamento com o médico e a secretária.

g) O comportamento civilizado e adequado: $\mathrm{O}$ médico sabe identificar o profissional com postura ideal para a profissão de propagandista. Dessa forma, ter boa postura, usar vestimentas adequadas e ser educado são diferenciais que influenciam no sucesso deste 
profissional. E porque não citar aqui também o profissionalismo e ética, pois muitos colegas de campo visam apenas o momento, e acabam se perdendo falando de maneira deselegante dos concorrentes, seja do produto ou o próprio colega, o que na maioria das vezes, acaba prejudicando-o.

h) A arte e o dom da comunicação eficaz: Uma comunicação limpa e objetiva facilitará o entendimento do produto oferecido. Para se comunicar bem e de forma eficaz faz-se necessário conhecer bem seu cliente. Este é um ponto fundamental, pois não se deve tratar os clientes da mesma forma, pois cada pessoa possui sua individualidade e faz-se necessário respeitar a essência de cada um. Cada médico e secretária precisam ser tratados da maneira cordial e agradável que o seu relacionamento com eles permitir.

\section{Conclusões}

As companhias farmacêuticas vêm atravessando uma fase crítica, além de lidar com um mercado altamente competitivo, necessitam aumentar sua produtividade e lucratividade o que tem sido um dos seus grandes desafios atualmente. A indústria farmacêutica está diante de um novo cenário: chegada dos genéricos, patentes quebradas, novos laboratórios e lançamentos de medicamentos com o mesmo princípio ativo. Dessa forma, com o aumento da concorrência e a segmentação do mercado prioriza-se não só a sobrevivência, mas, também, a assertividade diante dos concorrentes para alcançar os objetivos propostos.

A excelência é cada vez mais o objetivo das organizações. Trabalhar neste sentido é olhar para todos os componentes da estrutura organizacional. É desenvolver estratégias orientadas para os resultados e o impacto desses resultados, não apenas os resultados técnicos e econômicos, mas também os resultados ao nível da satisfação dos colaboradores e sobretudo dos clientes (NEVES; PEREIRA, 2012).

O propagandista é o elo entre as companhias farmacêuticas e o médico, é através deste profissional que as empresas estabelecem uma forte ligação com o seu cliente foco, o médico. Dessa forma, por ser a pessoa mais capacitada e com um conhecimento técnico e comercial adequado este profissional é o que está apto para esclarecer todas as dúvidas sobre os medicamentos. Assim, as visitas aos consultórios e hospitais tem por objetivo informar aos médicos sobre as medicações, quer sejam lançamento ou não, e tentar convencê-lo de iniciar as prescrições quando necessário. Esta função não está limitada apenas a transmissão de informações sobre o medicamento divulgado, mas busca-se estabelecer uma parceria junto a classe médica a fim de obter os resultados almejados. 
É importante ressaltar que a visita as farmácias tem se mostrado um diferencial do propagandista no setor, visto que através deste contato com os balconistas e farmacêuticos, pode-se informar sobre lançamentos, verificar estoque e saída de produtos, fazer colocação de novas apresentações além de orientar toda equipe da farmácia sobre descontos, programas de desconto e promoções.

Tendo por objetivo deste, "Destacar a importância do profissional de propaganda médica para a indústria farmacêutica, médicos e pacientes", principalmente no Vale do São Francisco, entre as cidades de Juazeiro-Bahia, Petrolina-Pernambuco, e cidades circunvizinhas, foi alcançado plenamente, pois os autores encontraram embasamento teórico e prático para tal, extraindo então, os pontos primordiais que norteiam as diretrizes deste Artigo.

No que diz respeito ao problema de pesquisa proposto de certificar "Qual a importância do profissional de propaganda médica?", foram relacionados inúmeros diferenciais com relação a estes profissionais, que reflete nos resultados, financeiros inclusive, para as indústrias farmacêuticas que os contratam, assim como, para seus clientes médicos, e de forma indireta e direta, os pacientes, que tem a oportunidade de receber a prescrição dos produtos propagados e de encontrar de forma mais fácil e nos lugares mais distantes estes produtos/medicamentos, que os levarão a uma vida mais saudável.

Para futuras pesquisas, fica a sugestão de uma pesquisa relacionada ao Perfil do Profissional de Propaganda Médica, dedicado à região do Vale do São Francisco e adjacências, tendo como base seu padrão sócio cultural, econômico e relacionado à faixa etária destes profissionais.

\section{Referências}

ABIFARMA - Associação Brasileira da Indústria Farmacêutica. Disponível em: http://www.abifarma.com.br/ Acesso em março de 2020.

AGUIAR, C. Propagandista: a estratégia no cotidiano. Revista Up Pharma, nº160 - Ano 39 - Mai/Jun - 2016.

AGÊNCIA NACIONAL DE VIGILÂNCIA SANITÁRIA (ANVISA). Política vigente para a regulamentação de medicamentos no Brasil. 2004. Disponível em: www.anvisa.gov.br/medicamentos/manua_politica_medicamentos.pdf. Acesso em: 26/03/2020.

BRASIL. Lei $\mathbf{n}^{\circ} \mathbf{6 . 2 2 4}$, de 14 de julho de 1975. Disponível em: http://www2.camara.leg.br/legin/fed/lei/1970-1979/lei-6224-14-julho-1975-357699publicacaooriginal-1pl.html. Acesso em 21 de mar 2020. 
BREGANTIN, D. Treinamento deve Desenvolver a Comunicação Participativa do Representante com o Médico. Revista de Marketing Farmacêutico, São Paulo: [s.n], p.44, jun./jul. de 2002.

CESAR, T. Marketing de relacionamento e a indústria farmacêutica. Salvador: UNIFACS, 2005. p. 01-10.

DAS, A. Pharmaceutical industry and the market: the case of Prozac adv other Antidepressants. Asian Journal of Psychiatry 4 (2011) 14-18.

FASSOLD, R.W. \& GOWDEY, C.W. Estratégias mercadológicas da indústria farmacêutica e $o$ consumo de medicamentos. Disponível em: http://www.scielo.br/scielo.php?script=sci_arttext\&pid=S0034-89101983000500003

FORTES, C. Integração e treinamento do novo propagandista médico. UniRitter Laureate International Universites - Curso de Pós-Graduação em Negócios (MBA em Gestão de Pessoas), 2017.

IMS Institute for Healthcare Informatics. The Global Use of Medicines: Outlook through 2015. May 2011.

KAPPE, E. R. The Effectiveness of Pharmaceutical Marketing. Erasmus University Rotterdam, 2011.

KESIC. D. Strategic analysis of the world pharmaceutical industry Management, 1.v. 14. P 59-76, 2009.

KOTLER, P. Administração de marketing. Tradução: Ailton Brandão. São Paulo: Atlas 1998.

Philip; SIMON, F. A construção de Biomarcas: levando a biotecnologia aos mercados globais. Porto Alegre: Bookman, 2004.

KREMER, S. T. M; BIJMOLT, T. H. A; LEEFLANG, S. H. P.; WIERINGA, J. E. Generalizations of the effectiveness of pharmaceutical promotional expenditures - Intern. J. of Research in Marketing 25, 234-246, 2008.

MUSSOLINI, N. O Marketing na prática. Revista Uppharma -Ano 32, no. 120 - São Paulo, 2010. p. 08. Disponível em: http://www.dpm.srv.br/revista/120/120.pdf. Acesso em: 06 de Abril de 2020.

NASCIMENTO, A. C. Avaliação da propaganda Farmacêutica e do relacionamento do propagandista junto à classe médica. Rio Grande do Sul: UFSM, 2008. P.50-130.

NETZ, C. Idéias e soluções para você brilhar na gestão dos negócios. Exame, 15 de julho de 2001. p. 118-119.

NEVES. C; PEREIRA, F. Gestão de Emoções: Coaching no âmbito da gestão organizacional. I Congresso Internacional de Inteligência Emocional e Educação "Investigar e Intervir para Mudar Escola Básica Comendador Ângelo Azevedo," Oliveira de Azeméis 6, 7 de julho de 2012.

ROCHA, R. R. V. da. Elaboração e aplicação de um modelo de gestão do conhecimento adaptado para o departamento comercial de uma indústria farmacêutica. Porto Alegre. Dissertação de Mestrado em Administração, Universidade Federal do Rio Grande do Sul, 2002.

SILVA, J.V.; LOVATO JUNIOR, V. O perfil do propagandista farmacêutico no Brasil. Revista da Faculdade de Ciências Médicas de Sorocaba. São Paulo, v.18, n. 3, p. 165-168, nov. 
2016. ISSN 1984-4840. Dispoinível em: $\underline{\text { http://revistas.pucsp.br }}$ lindex.php/RFCM/article/view/28684. Acesso em 21 mar. 2020.

VIEIRA, T. R. A formação profissional de um Propagandista-Vendedor. Monografia PósGraduação em Gestão Estratégica em Técnicas de Vendas e negociações, AVM Instituto Universidade Cândido Mendes, 2011.

WAZANA, A. Physicans and the pharmaceutical industry: is a gift ever just a gift? J. Am. Med. Assoc., v. 283, n. 3, p. 373-380, 2000.

\section{Como citar este artigo (Formato ABNT):}

SANTOS, Bruno Lima e; SANTOS, Thais Angela Rodrigues dos; CAFFÉ FILHO, Hesler Piedade. A Importância da Propaganda Médica para o sucesso da Indústria Farmacêutica e a Diferença que o Propagandista faz para a Classe Médica e seus Pacientes. Id on Line Rev.Mult. Psic., Maio/2020, vol.14, n.50, p. 914-928. ISSN: 1981-1179.

Recebido: 05/05/2020

Aceito: 13/05/2020 